\title{
La palabra chileno nada puede expresar: poesía de origen mapuche
}

\author{
Magda Sepúlveda Eriz \\ Pontificia Universidad Católica de Chile \\ msepulvu@uc.cl
} Nota: Este artículo se inscribe dentro del proyecto Fondecyt regular No 11.20.264 cuya investigadora
responsable es quien suscribe este artículo.

La poesía de origen mapuche escrita a fines del siglo XX y comienzos del siglo XXI elabora una correlación entre maneras de habitar y formas de hablar. Un grupo de textos, que describe el habitar rural en la naturaleza, privilegia la publicación de textos bilingües español-mapudungún. Otro grupo de poemarios, que marca la enunciación desde las ciudades de provincia, diseña textos metapoéticos donde reflexiona sobre el conflicto de hablar español de Chile. Y un tercer grupo de libros de poesía codifica la reapropiación de la metropolí, usando lenguas urbanas, como elsplanglish y el coa, mezclado con el mapudungún.

Palabras clave: Poesía mapuche, territorio, letra.

Mapuche poetry written in the late twentieth and early twenty-first establishes a correlation between ways of living and ways of speaking. A group of texts, describing rural liefestyle in nature, favors the publication of bilingual texts. Another group of poems, which marks the statement from the provincial towns, designs metapoetic texts where he reflects on the conflict to speak Spanish in Chile. And a third group of books of poetry encodes the reappropriation of the metropolis, using languages such as spanglish and coa, mixed with mapudungún.

Keywords: Mapuche Poetry, Land, Letter.

* Una primera versión de este trabajo fue leída en el XVIII Congreso Internacional de Estudios Literarios (SOCHEL), Osorno, en noviembre de 2013. Forma parte del proyecto Fondecyt 1100662, "R epertorios en coexistencia e interf erencia en la poesía indígena hispanoamericana actual", del que soy investigadora responsable y cuyos coinvestigadores son los Dres. Iván Carrasco y Oscar Galindo. 
Camino por el centro de Santiago de Chile. Llego hasta la Plaza de Armas, llamada así porque allí se guardaban justamente las armas en la época de la Conquista. Me detengo en laesquina que contiene la escultura de un indígena En la otra esquina está la estatua ecuestre del conquistador. El monumento al español es la representación de un personaje histórico reconocible, Pedro de Valdivia. La escultura al indígena es la representación de un rostro mapuche sin nombre. Además solo tiene cabeza, su cuerpo no forma parte de la obra. Tanto la ausencia de nombre como de cuerpo me parecen dos gestos simbólicos. Veo en estas dos esquinas la repetición de la historia oficial, a pesar de que la escultura del indígena fue hecha en la década de los 90, a fines del siglo XX. La representación insiste en la narrativa decimonónica de Francisco Encina, donde se elabora el heroísmo de los españoles y se deja la barbarie para los indígenas. Las luchas de los indígenas contra las ciudades son contadas como desastres:

En la madrugada del 11 de septiembre, los indios, resguadados por la misma empalizada que protegía la ciudad, arrojaban nubes de flechas y piedras que los españoles lograban esquivar hasta el alba. Con la luz consiguieron contrarrestar el ataque, pero eran muy pocos y al incendio de los ranchos de paja hubiera seguido el exterminio de todos los españoles si Inés de Suárez no hubiera salvado la situación, convenciendo a los españoles de la conveniencia de degollar a 7 caciques que Valdivia había retenido en la ciudad, y arrojar sus cabezas entre los aterrorizados indios. La carga final, en la que la propia Inés de Suárez participó con su cota de malla, definió la pelea y la supervivencia de Santiago (Francisco Encina, Historia de Chile, Tomo I).

Encina describe a los españoles como valientes cuando narra la destrucción de Santiago en 1541, y no se refiere al valor de las fuerzas dirigidas por el cacique Michimalonco. Todavía no valoramos el gesto indígena y no nos reconocemos en esos cuerpos. La ciudad letrada está en deuda con el mundo indígena.

Las ciudades fueron, para el imperio colonial español, una forma de llevar a cabo su sometimiento. Ya Ángel Rama ha relacionado el poder político con la distribución espacial, indicando que los tres lugares estratégicos para la dominación, el correo, la iglesia y la alcaldía, se instalaron en el centro de la ciudad. El correo posibilitaba la comunicación con la metrópoli imperial; la iglesia procuraba atraer fieles para el nuevo universo de valores y la alcaldía permitía la subyugación a las leyes imperiales. Así, en la ciudad letrada, la escritura y el poder conformaban una unidad ideológica y territorial. Las ciudades coloniales fueron pensadas como ejercicio civilizatorio, y por tanto, se menospreció y se intentó acabar con las formas precolombinas de habitar. Incluso en los lugares donde existían ciudades, como Tenochtitlan, en México, que era una urbe más grande y compleja que cualquiera europea de la época, los conquistadores edificaron su ciudad sobre ella. En Chile, la situación del habitar era otra, pues los mapuches tenían un concepto diferente de poblar. Para ellos, habitar era y es vivir en y como la naturaleza. Esta forma está en la palabra del mapudungún lof, que alude a un espacio de convivencia 
territorial y social "basado en la justicia y la reciprocidad" (Consejo de todas las tierras 10) practicado por quienes se conocen y se reconocen entre sí, como pertenecientes de una misma identidad colectiva, dada por la memoria del espacio físico y de los ancestros que han habitado en él. Esta noción dista bastante de la idea de ciudad que se define como una agrupación de desconocidos que no se reconocen en relaciones de reciprocidad, sino en obediencia a una justicia escrita ${ }^{1}$.

La literatura de origen mapuche de fines del siglo XX y comienzos del XXI ha poetizado la relación entre el territorio y la letra. Destacan tres maneras de simbolización. La primera modalidad consiste en la elaboración de un territorio maravilloso donde el humano convive armoniosamente con elementos naturales. Quienes participan de esta modalidad reproducen oral y escrituralmente sonidos de la naturaleza y/o suelen escribir libros bilingües en español y mapudungún. La segunda línea está formada por quienes marcan su situación de enunciación desde la provincia y escriben en castellano, pero con una conciencia metapoética sobre las dificultades de hablar la lengua del conquistador. La tercera modalidad literaria la integran los poetas que reclaman simbólicamente la metroplí como territorio mapuche y trabajan sobre una verbalización que hibridiza las lenguas urbanas, el coa, el punk, el rap, con el mapudungún. Estas formas de codificar define grupos de poetas. Los paradigmas de la primera modalidad son los poetas Elicura Chihuailaf ${ }^{2}$ (1952) y Leonel Lienlaf (1969). En la segunda línea, Jaime Luis Huenún (1967), Bernardo Colipán (1967) y Juan Paulo Huimirilla (1973). En la tercera modalidad Eliana Pulquillanca (1963) y David Aniñir (1970), entre otros.

\section{Escuchar la tierra. El ave de tu idioma}

Elicura Chihuailaf publica El invierno, su imagen y otros poemas azules en 1991. Es un libro donde la mayoría de los poemas tienen una versión en español de Chile y una en mapudungún. El poeta habla las dos lenguas, no hay ni traductor ni traducción. El poema que abre el libro, "La llave que nadie ha perdido" es un arte poética que remarca que su poesía se hace desde la sonoridad de la naturaleza:

\footnotetext{
1 Para Kotkin, los ríos, mares, rutas comerciales o espacios verdes pueden ayudar a iniciar una gran ciudad, o contribuir a su crecimiento, pero no pueden sustentar su éxito a largo plazo, pues ello está vinculado al valor que las personas le asignen a la experiencia de la vida urbana, esto es, "a coexistir e interactuar con extraños ajenos a su clan o tribu. Ello les exigía desarrollar nuevas formas de conducta codificada, determinar qué era lo normalmente aceptable en la vida familiar, el comercio y el discurso social. En tiempos antiguos, normalmente era el clero el que dictaminaba sobre tales materias" (Kotkin 289).

2 E. Chihuailaf ha publicado los poemarios El invierno y su imagen (1977), y En el país de la memoria (1988), donde una serie se refiere a la ciudad. Es un libro que habla de la herida de ser ciudadano de segunda clase. Posterior a él, el autor ha continuado en un registro utópico donde se inscriben El invierno y su imagen y otros poemas azules (1991), De sueños azules y contrasueños (1995) y A orillas de un sueño azul (1991). En prosa destaca Recado confidencial a los chilenos (1999). Eliana Pulquillanca ha publicado Raíces del canelo (2004). Juan Pablo Huirimilla ha publicado El ojo de vidrio (2002) y Palimpsesto (2005). Jaime Huenún ha escrito los poemarios Ceremonias (1999) y Puerto Trakl (2001). Bernardo Colipán ha publicado el libro de testimonios Pulotre (1999), el poemario Arco de interrogaciones (Santiago: LOM, 2005) y el texto testimonia poético Forrahue (2012). David Aniñir ha publicado los poemarios Mapurbe (2005) y Haykuche (2008).
} 
La poesía no sirve para nada, me dicen y en el bosque los árboles se acarician con sus raíces azules y agitan sus ramas el aire, saludando con pájaros la Cruz del Sur

La poesía es el hondo susurro de los asesinados

el rumor de hojas en el otoño, la tristeza por el muchacho que conserva la lengua pero ha perdido el alma

La poesía, la poesía, es un gesto, el paisaje tus ojos y mis ojos muchacha, oídos corazón la misma música. Y no digo más, porque nadie encontrará la llave que nadie ha perdido

Y poesía es el canto de mis antepasados el día de invierno que arde y apaga esta melancolía tan personal

El poema está constituido por instancias que refieren a sonido: "agitan sus ramas", "saludando con pájaros", "susurro de los asesinados", "rumor de hojas", "la misma música", "oídos" y "canto de mis antepasados". Esa escucha tan acuciosa solo puede provenir de la melancolía o tristeza por una pérdida que no se declara fenecida. Esa pérdida que permanece aun viva es, en el poema, la cultura mapuche. El hablante se constituye como poeta en la medida en que es capaz de escuchar los sonidos de la naturaleza y el canto de los ancestros, y esa llave no se haperdido. Si mapudungún significa literalmente habla de la tierra, aquí el poeta es quien escucha la naturaleza e intenta una mímesis, semántica y/o fónica de esa escucha en sus textos. El poeta se autodefine como tal en tanto está en solidaridad con los sonidos de la naturaleza y el relato de sus antepasados.

Neruda decía en "La lámpara en la tierra": "las iniciales de la tierra estaban escritas.// Nadie pudo recordarlas después: el viento /las olvidó, el idioma del agua / fue enterrado, las claves se perdieron" (Neruda 7). Neruda menciona aquí un idioma del viento, un idioma del agua y un idioma de la tierra. El poeta establece un vínculo con la vibración de la naturaleza, que es propiamente el sonido. Él, como todos los poetas, está atento a todos los sonidos, pero cree que esa capacidad de imitar los sonidos de la naturaleza se perdieron. Sin embargo, si hoy escuchara a Lorenzo Aillapán sabría que una parte de los humanos se encargó de conservarlos. Este poeta mapuche se autonombra "hombre pájaro", en virtud de que puede reproducir, haciendo uso de todo su aparato fónico, los sonidos de la gran mayoría de las aves que habitan el sur de Chile. Sus poemas recopilados por editorial Pehuén el 2003, son todos bilingües. Cada uno de ellos lleva el nombre de un pájaro. Los poemas en mapudungún son onomatopéyicos de diversos sonidos de cada pájaro, su piar, su vuelo y su manera de comer entre otras conductas animales. Aillapán conserva las claves.

La metrópoli es descrita por este grupo de poetas como un lugar donde los sonidos corresponden a objetos que se cierran. El oído gigante define 
la poética de Chihuailaf. Por eso, para él, estar en la ciudad esc escuchar sonidos que confunden. En el poema "Sueño de agua turbia" rememora su estadía en Santiago:

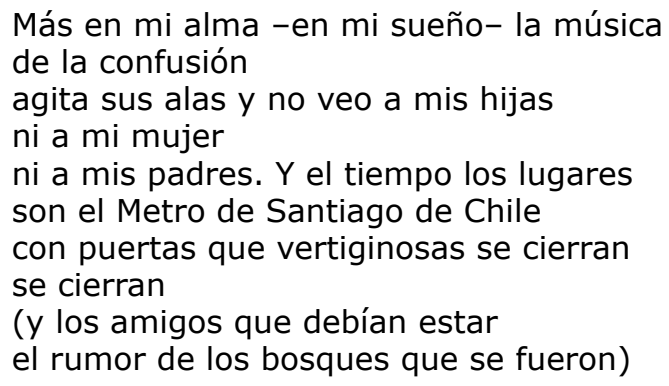

(Chihuailaf: 199183 ).

El sonido de la ciudad corresponde, en el poema, a puertas que se cieran, que connota la discriminación en una ciudad que se piensa blanca. En ese duro escenario, el hablante incluso poetiza mediante sonidos, el abandono de los amigos, como "rumor de los bosques que se fueron". Esa forma de poetizar lo acerca a su cultura. Y esas son las claves que no se perdieron.

La ciudad no es el lugar de las palabras que el poeta busca. Ellas están en su comunidad, donde la naturaleza forma parte de lo vivo y las personas se juntan a dialogar. En el poema "Sueño azul" poetiza esa manera de habitar:

\author{
La casa Azul en que nací \\ situada en una colina \\ rodeada de hualles, un sauce \\ nogales, castaños (...) \\ En invierno sentimos caer los robles \\ partidos por los rayos (...) \\ Por las noches oímos los cantos \\ cuentos y adivinanzas \\ a orillas del fogón \\ respirando el aroma del pan (...) \\ Hablo de la memoria de mi niñez \\ y no de una sociedad idílica
}

(Chihuailaf: 1999 25)

El poema crea un modo de habitar donde el entorno natural forma parte de la historia y el grupo social cultiva una memoria que lo vuelve comunidad. La casa descrita en el poema tiene una particularidad, está asentada en un lugar específico, donde hay cierto tipo de árboles y llegan ciertas especies de aves. Entonces no es el espacio ni el tiempo moderno lo poetizado, sino una manera de vivir donde los elementos naturales forman parte de la memoria histórica de la comunidad. 
Leonel Lienlaf publica Se ha despertado el ave de mi corazón en 1999. Es un poemario enteramente bilingüe. En el libro, la figura del poeta se constituye como aquel al cual le habla la tierra, el agua y los pájaros. El poema "Palabras dichas" funciona como un arte poética:

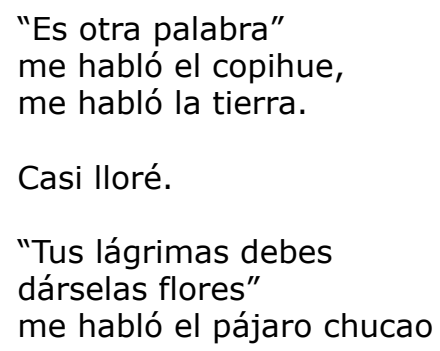

(Lienlaf: 1999 59)

En el poema, el hablante es investido como poeta por el copihue, la tierra y un ave. Estos elementos aparecen personificados, hablan, pero no es tan solo una figura retórica. En la poesía mapuche efectivamente existe una visión de mundo donde la naturaleza está viva y produce sonidos.

La ciudad para Lienlaf tiene un sonido subterráneo y es el ruido de sangre que corre bajo ella. Temuco es descrito como territorio indígena usurpado. La descripción es efectuada por los elementos naturales de la ciudad, el río Cautín y el cerro Ñielol:

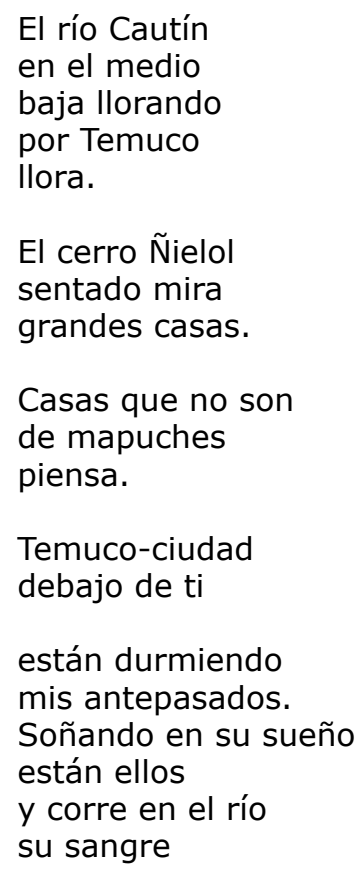


La personificación de los elementos naturales, el río llora y el cerro piensa, corresponde a una forma de entender el espacio. La ciudad no vale en tanto urbe, en este poema, sino que interesa por los ementos naturales que definen su hábitat. Tanto el cerro como el río forman parte del archivo mapuche, cuyos documentos son los cerros, los ríos, la flora y la fauna. El paisaje es el testimonio de la pertenencia de ese territorio a sus habitantes primeros y para habitar ese paisaje hay que hablar su lengua, el lenguaje de la tierra. Por ello, la mayoría de los textos que enuncian desde lo rural son bilingües español-mapudungún. Se ha despertado el lenguaje en mi corazón, se ha despertado el ave de mi corazón.

\section{Habitar la provincia. Obligado al español}

Una segunda línea de poetas publica libros en español que introducen al interior de cada texto algunas palabras en mapudungún. La mayoría de ellos son poetas que remarcan una situación de enunciación provinciana, aunque no necesariamente vivan ya en las ciudades de provincia. En ellos se da una reflexión metapoética donde se asocia el pertenecer a la ciudad con aprender el español. A este grupo pertenecen Jaime Huenún, Juan Pablo Huirimilla, Bernardo Colipán y Adriana Paredes Pinda, entre otros.

Jaime Huenún publica en 1999, Ceremonias. Cada una de las partes del libro, "Ceremonia del amor", "Ceremonia de la muerte" y "Ceremonia del regreso", poetiza la forma en que la cultura mapuche vive cada una de esas instancias. "Ceremonias de la muerte" aborda una serie de asesinatos masivos efectuados en reducciones mapuches. El poeta diseña para relatar algunos de estos crímenes la voz de un mapuche que no porta los saberes que se exige al ciudadano:

UNO

(FORRAHUE)

"...alzaban sus manos ensangrentadas al cielo..."

(Diario El Progreso de Osorno, 21 de octubre de 1912)

No hablábamos chileno, mi paisano, castellano que lo dicen.

Copihue sí, blanco y rojo,

flor de michay,

chilco nuevo.

No sabíamos de Virgen ni de Cristo, padrecito, ni del Dios en las Alturas.

Jugábamos tirándonos estiércol de caballo en los potreros;

robábamos panales a los ulmos y a los moscos, y pinatras a los hualles de la pampa;

mirábamos desnudas bañarse a las hermanas con manojos de quillay en el arroyo. 
Malo era.

Sí.

Por eso vino envidia y litigio y carabina

(...)" (Huenún: 1999 31)

El escritor deposita en un sobreviviente de la matanza de Forrahue la descripción de todas las acusaciones contra esa comunidad mapuche. El sobreviviente se encuentra ahora, después de su huida por montañas y barrancos, en una ciudad de provincia. Esta localización se marca en las referencias apelativas del hablante: "mi paisano", "padrecito", "amigo" y "mamita". En las acusaciones que justifican el exterminio están no hablar castellano y no conocer la fe católica. El hablante se identifica con otra lengua, "copihue sí", vale decir, la lengua de la tierra, el mapudungún. En la ciudad, el hablante ha sobrevivido y habla castellano, pero para ello ha debido renegar de su cultura, "malo era". Entonces ciudad y lengua coinciden.

Juan Paulo Huirimilla en su libro Palimpesto (2005) plantea la ciudad provinciana como espacio del extr avío para el sujeto $\mathrm{m}$ apuche. El a utor crea un campesino mapuche que describe su habitar en la urbe local y que va mostrando en sus ropas, en las canciones que escucha y en su modo de ser otro tiempo histórico. Por ello, en la descripción, su personaje es un palimpesto temporal que contiene elementos de todos los tiempos. Huirimilla presenta el desacomodo de una subjetividad que entiende el tiempo de manera diferente, en relación con ciclos naturales y, por ello, en la ciudad se presenta como un personaje fuera de época, un extemporáneo, alguien a quien le llega tarde la moda:

Yo cazador recolector urbano de chaqueta $\mathrm{e}^{\prime}$ cuero pintado a la gomina nacido de la chingada de Pedro Eriazo

Hablo tartamudo por los muertos de mis antepasados con el ceño partido

parco de palabras se me ha perdido

el carnet de identidad.

-Siempre es el otro en el reflejo trizado de una fotografía-

La palabra Castilla o chileno nada puede expresar

(Huirimilla: 2005 136)

La urbe no es un lugar capaz de convertirse en un territorio personal para el personaje de Huirimilla, porque es un espacio que lo homogeniza hacia lo nacional. El documento de identidad que lo nombra "chileno" nada expresa para esta voz. A su vez, la fotografía del carnet es, para él, la representación de la tachadura en su identidad, pues lo indica chileno, una pertenencia que él rechaza. 
La serie de anulaciones tr ansforma finalmente al habitante mapuche en un fantasma. En ese estado de extravío, el sujeto de Huirimilla camina por los lugares degradados de la ciudad: bares, cantinas, prostíbulos y cines de tercera. El hablante traza un croquis urbano hilvanando los lugares donde se da la hibridez tercermundista que describió García Canclini: "procesos socioculturales en los que estructuras o prácticas discretas, que existían en forma separada, se combinan para generar nuevas estructuras, objetos y prácticas" (14). Así las rancheras, canciones propias de México, se escuchan en los sitios degradados de la ciudad provinciana. Para Carlos Monsiváis: "La canción ranchera es el gran golpe de una metafísica para las masas; allí está algo que sostiene reacciones y convulsiones ajenas al ámbito de la ciudad" (89); donde "el pueblo se desquita de la imposibilidad económica y cultual" (91), Ilorando la pérdida de su rancho y de su amada(o). Esta pérdida del rancho es el punto que toca la sensibilidad del hablante de Huirimilla, que desde su condición de campesino extraviado en la ciudad empatiza con los detractores mexicanos de la ciudad. Así, estos lugares, como la cantina, el prostíbulo y el cine que da películas viejas, se constituyen en zonas de hibridez latinoamericana, donde se da la mixtura de diversos productos del continente.

Bernardo Colipán publica Arco de interrogaciones el 2005. El libro poetiza la pertenencia del hablante a la cultura mapuche y las salidas obligadas por medio de la escuela y sus enseñanzas de lengua y de historia. Arco de interrogaciones es efectivamente un arco construido en el rito del nguillatún. Esa es la pertenencia. La salida es la educación obligatoria blanca. El poema se llama "Ese difícil oficio de leer a Encina":

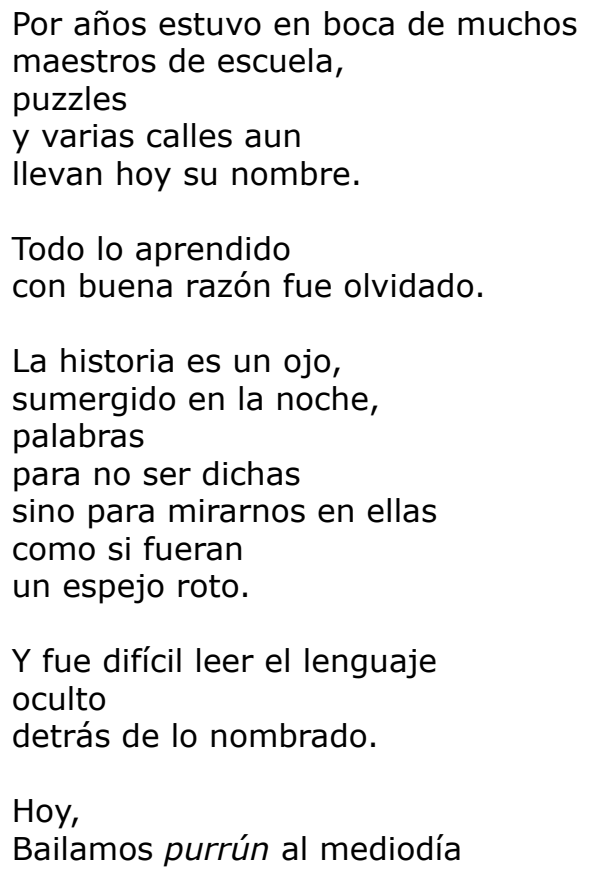

(Colipán: 2008 107) 
Colipán poetiza la historia canónica de Chile como sumergirse en la noche o mirarse en un espejo roto. El poeta pliega esa historia sobre las calles de la ciudad que llevan aun el nombre de los principales represores de los indígenas como Cornelio Saavedra. Esos nombres continúan apareciendo en los puzles, es decir, son de un conocimiento básico para todo ciudadano chileno. La ciudad urbanística y la ciudad letrada coinciden para Colipán en su atropello al pueblo mapuche. Por ello, hay que entrar a otro espacio, aquel donde se baila purrún, que es un conjunto de danzas que imitan el vuelo de ciertas aves.

Adriana Paredes Pinda había sido publicada solo en antologías, hasta antes de su poemario Üi (2005). En los poemas antologados, Paredes Pinda realiza una serie de reflexiones metapoéticas, que dan cuenta del lugar conflictivo que ocupa, para ella, hablar en español. Ella quisiera una voz más híbrida entre español y mapudungún, tal como poetiza en "Destino".

que mi lengua ha de salirse de sí misma

y pactar con el wekufe que la ampara

su reverberación de pájaros y aromas

que mi lengua ha de partirse

-ha de partirse- dicen

por porfiada y lujuriosa

te recuperaré

y mi lazo

rodeará acaso el aura de tus sílabas magnolias

ah mi pinda lengua

lengua mía y de todas sin misericordia

(Paredes Pinda 427)

La hablante se posiciona recibiendo un mandato, debe partir su lengua, es decir, se le aconseja integrar el mapudungún, que será un nacimiento de pájaros. Al situarse como mandada por una fierza externa, ella se da el lugar de machi. Desde ese rol, la hablante desarollará una "pinda lengua", es decir, una lengua que llevará su marca de subjetividad. Eso corresponde a la definición de sujeto moderno. Más aun si analizamos la palabr a "pactar", Pinda afirma su voluntad de negociar con la lengua que sostiene al wekufe, el colonizador. Ella se declara enamorada de esa lengua, "porfiada y lujuriosa". Por tanto, en su proyecto apuesta por la hibridez cultural. Sobre la hibridez cultural en la poesía de mujeres mapuches, la crítica Fernanda Moraga ha indicado: "presentan cuerpos subjetivados en tensión, asumiendo experiencias, muchas veces, colmadas de contradicciones, las que emergen j ustamente, como posibilidades de desplazamientos en la iteración cultural colonialista, es decir, justamente, este señalamiento de unas identidades problematizadas, mestizadas es una de las condiciones de su posibilidad cultural" (Moraga 228). Moraga suma en este grupo a Roxana Miranda Rupailaf y Maribel Mora. De ellas, quien trabaja la relación territorio y lengua es Paredes Pinda, la cual poetiza la incorporación híbrida de castellano-mapadungún como solución a la convivencia citadina con el chileno. 
El sometimiento que pide la ciudad es el lenguaje español de Chile, por ello la reterritorialización no es tan solo una conquista de espacios físicos, sino también de la lengua originaria. De manera que la escritura bilingüe de muchos de estos poema rios o la hibridez entre un español de Chile y el mapudungún son hechos decisiv os en la construcción estética y en la protesta cultural de esta poesía. La apertura al habla del mapudungún implica romper la prohibición de hablar esa lengua materna que fue total en las escuelas ha sta fines del siglo XX. Así lo indica uno de los testigos convocados por Chihuailaf: "Recuerdo siempre lo que me contaba mi padre que a los catorce años fue al colegio, a una escuela de curas de Panguipulli. Mi padre en ese tiempo no hablaba castellano, lo aprendió en el colegio. Mi padre dice que si no se sabía bien la lección lo dejaban horas hincado en el patio o en la capilla con arvejas o arena en las rodillas. ...Así aprendió a hablar y a leer el castellana Entonces una de las cosas que él asumió -por sus sufrimientos- fue que sus hijos no hablaran mapuzugun. Hace quince o veinte años había que tratar que la Identidad apareciera lo menos posible" (Chihuailaf 1999:179).

Este grupo de poetas v e la ciudad de provincia como un espacio de despojo de su cultura, que se in icia con la enseñanza monolingüe del español, en la escuela, y termina con el acoso y el exterminio de las reducciones mapuches de sus alrededores. La poeta y crítica Maribel Mora Curriao aprecia que este grupo "asume la poesía moderna y la condición de poeta para incorporar allí los elementos de su cultura propia a la que no han accedido libremente debido a los diversos procesos sociohistóricos de dominación cultural, sino que en muchos casos solo a través de un proceso de recuperación (Mora Curriao: 2012 331). Efectivamente ese ir y venir desde los espacios chilenos a los espacios mapuches y viciversa encuentra, en la retórica metapoética, la codificación para expresar todas sus dudas y distancias.

\section{Devuélvannos la metrópoli. Con coa y punk volvemos a hablar}

La tercera línea de la relación entre territorio y habla está formada por poetas que son mapuches metropolitanos. Según los datos del censo nacional del año 1992, el $80 \%$ de los mapuches ya residían en zonas urbanas. Algunos de los poemas de Eliana Pulquillanca y Da vid Aniñir se inscriben dentro de esta línea. Eliana Pulquillanca sitúa literariamente en la periferia de Santiago la instalación de su ruka -poema recopilado en la antología de Mora y Moraga- y la consecuente transformación del lugar:

Aquí en medio de los fierros crece la totora.

Crece, se empina

cual águila buscando su carne

en este bosque de polvo

sin miedo y con epew en los labios.

Aquí el círculo azul guarda sus espíritus

y se aprecia la planicie gris de la ciudad. 
Los choique vuelven a nidar
el pangue a su manada.
nacen nuestros hijos.

Santiago de Chile

habitado por mapuche desde siempre.

Antiguamente el Mapocho sonreía

y la ruka descansaba en sus orillas

(Pulquillanaca 428)

El poema incorpora el habla metropolitana, como "en medio de los fierros", para referirse al acopio de estructuras metálicas desechadas que luego es vendido por kilo. El poema comienza con la referencia a un lugar "aquí", que resulta ser, en la penúltima estrofa, Santiago, pero enunciado desde los barrios populares, donde, en los patios, se almacena el fierro que se va a vender por kilos. A pesar de la acumulación de desechos y de la pobreza, los elementos del hábitat mapuche crecen igual, como la totora, el pangue o la nalca y así llegan las aves, como el choique, a reterritorializar mapuche ese espacio metropolitano. Además la familia tiene descendencia. La creación de un entorno natural en la metropolí junto a los hijos, forman los elementos centrales de esta tercera estrategia literaria para representar la reapropiación de los territorios enajenados.

Aniñir en Mapurbe (2005) crea una voz que habla desde y sobre los mapuches en la gran ciudad. Son los 'mapuches de hormigón', habitantes de la periferia santiaguina nombrada a través de La Pintana, una comuna escuálida en recursos económicos. Aniñir cambia la pertenencia, ya no gente de la tierra, sino mapuches del hormigón. La alteración es compleja, pues hay una modificación en la definición identitaria. A la noción de "gente de la tierra: mapuche", se suma una caracterización propia del sujeto híbrido que vive entre-culturas. Bhabha ha dicho que los espacios in-between son "espacios donde se elaboran estrategias de identidad que inician sitios innovadores de colaboración y cuestionamiento de la sociedad" (Bhabha 18). La innovación en este poemario es la mezcla entre el punk, la cultura mapuche y la cultura de los delincuentes. De la misma forma, el poemario mezcla palabras en mapudungún, coa y neologismos americanos, dando cuenta de los espacios 'entremedio' en que vive el sujeto de estos poemas.

Aniñir actualiza la identidad, la saca del mito y la adviene al tiempo histórico. Sus personajes se apropian de las estrategias del centro, como el punk, y lo resemantizan como forma de resistencia. De esta forma, el punk vuelve en Santiago de Chile a recuperar cierta cuestión étnica que tuvo en sus inicios británicos. Ese origen fue la protesta del inmigrante caribeño en Londres, tal como lo relata Dick Hebdige en Subcultura: "El festival caribeño, con todas sus connotaciones turísticas de gente feliz y variopinta bailando alegres calipsos, con exóticas vestimentas, se convirtió de golpe, e inexplicablemente, en una amenazadora congregación de negros furiosos y policías acosados" (Hebdige 41). David Aniñir car acteriza a sus personajes como punky-mapuche recuperando este origen étnico y subversivo del punk, que 
usó el estilo vestimentario como forma de resistencia, dándole al cuerpo la categoría de soporte del que carece de voz (Spivak). Aniñir trabaja en la tiple exclusión, creando un personaje mapuche, pobre y mujer:

Maria Juana La mapunky de la Pintana gastarás el dinero del antiquísimo vinagre burgués para recuperar lo que del no es.

Volarás sobre la nube de plata arrojarás bolas y lanzas de nieve

hacia sus grandes fogatas

Eres tierra y barro y no estas ni ahí con ÉL mapuche sangre roja como la del apuñalad o

Eres Mapuche en F. M. (o sea, Fuera del Mundo) eres la mapuche "girl" de marca no registrada de la esquina fría y solitaria apegada a ese vicio, tu piel oscura es la red de SuperHiperArchi venas que bullen a gorgotones sobre una venganza que condena.

Las mentiras acuchillaron los papeles

y se infectaron las heridas de la historia. Un tibio viento de cementerio te refresca mientras de la nube de plata estallan explosiones elektricas llueven indios en lanza

LluviXkumey kuri Malén amuley wixage anay

(Aniñir 11)

En este poema, Aniñir representa a su personaje como fuera del mundo moderno, cuestión que se escenifica a través del significante F.M, con lo cual agrega que la modernidad es la fuente de esa exclusión.

Aniñir renueva ciertas miradas arcaizantes e idílicas sobre las culturas étnicas, resignificando el particularismo local indígena a partir de una corriente del imaginario masmediático como el punk. Esta transformación no es un signo de aculturación, es un nuevo modo de instalar los reclamos de su etnia. Así sucede en el poema "Lautaro", donde Aniñir retoma la figura del héroe épico poetizada por Ercilla, Neruda y Lienlaf, entre otros, pero lo sitúa en la contemporaneidad del siglo XXI: "Ciberlautaro cabalgas en este tiempo Tecno-Metal / tu caballo trotaen la red" (37). "Neo lautaro" (37) usa internet y efectúa el comercio del pirateo. El poeta rearticula la función del werkén o mensajero instalándola en el mundo de las comunicaciones digitales. Este Lautaro de Aniñir es bastante diferente de los otros Lautaros literarios como bien lo explica María José Barros: "Pablo Neruda instala el heroísmo del joven guerrero como un hecho del pasado $(y)$ describe su accionar por medio de verbos en pretérito (...). Lienlaf lo sitúa en el presente de la voz poética, pero como un espíritu que, desde esa condición incorpórea, incita a su gente. (En) el poema de David Aniñir, Lautaro (es) un mapuche habitante de la ciudad global, el nuevo espacio de la batalla épica" (Barros 38). 
Añiñir le da a Lautaro la materialidad necesaria para lograr lo expresado en el subtítulo de su libro: "venganza de raíz".

Desde una periferia que se instala en la globalización, Aniñir insiste en el conflicto de larga data de no tener tierra: "Oscura negrura of Mapulandia street / si, es triste no tener tierra / loca del barrio La Pintana / el imperio se apodera de tu cama" (11). El antecedente de sujeto expulsado de su territorio en el pasado histórico incide en su condición actual de ocupar los márgenes de la ciudad. Es un margen territorial y también político, por ello en "Oda al hambre", se evidencia un sujeto que no desea integrarse al sistema burgués de vida. Para rechazar el dinero del capitalismo, la voz hace una loa al hambre, en su valor de motor de la rabia social, a contraposición del banquete burgués que lleva a la siesta y a la inmovilidad. Los héroes de esta voz se mueven tecnológicamente por la ciudad. Los poemas de Aniñir están dirigidos por un deseo de reterritorialización que se inicia desde los bordes espaciales de la metrópoli, pero que usa la tecnología del siglo XXI para convocar hacia el cumplimiento de su anhelo.

La voz de este grupo de poetas interrumpe la ciudad imponiendo otra estética y otra política. Las preguntas que el crítico y poeta Luis Cárcamo Huechante se formula para el programa de radio "Wixage anai!" que trasmitía en español y mapudungún, son válidas también para esta poesía: "¿Qué se hace vibrar en el aire de la ciudad, si tenemos en cuenta que la mayoría de los habitantes de la capital chilena son monolingües y se imaginan como sujetos de ancestros hispanos y/o europeos? ¿Qué resonancias de sentido y sentidos se ponen en juego en esta irrupción sonora de los signos de un pueblo originario dentro de la ecología acústica de la sociedad chilena dominante?" (Cárcamo Huechante 352). Tanto en el programa de radio como en este grupo de poetas el lugar de enunciación es la metropolí, y en ambos, la metropolí está tomada.

\section{Comentarios y conclusiones}

La poesía mapuche escrita desde fines del siglo XX elabora una relación entre el lenguaje, uso del mapudungún, y el tipo de imagen que se posee del territorio. La poesía que privilegia la publicación de libros bilingües mapudungún-español compone la partitura de cantos de vida y esperanza para el lector urbano monolingüe español y para el lector bilingüe mapudungún-español. El lector urbano aprecia allí la recuperación de un vínculo privilegiado entre la experiencia de la fisicidad humana y la naturaleza. El lector bilingüe mapudugún-español ve allí una validación de su forma de habitar. Las poesías de este grupo crean sentidos nuevos para los sonidos de la naturaleza. Con ello, este proyecto escritural aspira a revertir la idea de "civilizar" al "salvaje". Esta estética trata de deconstruir lo "civilizado" y transmitirle una idea de belleza en relación con el ejercicio del uso de los sentidos y la contemplación.

El segundo grupo de poetas se caracteriza por publicar libros en español, introduciendo en ellos palabras en mapudungún, como tesoro lingüístico que ha escapado de la aniquilación. Estos textos se dirigen a un lector urbano letrado que pueda comprender referencias que van desde el historiador 
Francisco Antonio Encina hasta los románticos alemanes. Estos diálogos sitúan la cultura mapuche al mismo nivel y con los mismos derechos de otras culturas. Los textos recrean diversas instancias de agresividad sobre su cultura, como las masacres en las reducciones, la imposición del idioma español y la educación en una histora oficial que los señala como bárbaros. El reclamo presente en estos textos es el derecho a tener una ética propia y un control, como pueblo, de la producción y circulación del conocimiento en las ciudades de provincia.

El tercer grupo de proyectos escriturales publica en un español de código no letrado, donde el coa, las expresiones populares y el lenguaje juvenil tienen cabida. Su habla apela a un lector urbano capitalino que exhibe con rebeldía su marginalidad en la metropolí. Los grafemas escriturales usados por este grupo recuperan el trazo punky, el spanglish y la "mala ortografía", desafiando con ello las normas lingüísticas del código hegemónico. A la vez, este gesto asocia al grupo mapuche a otras comunidades marginales que han quedado fuera de las posiciones de privilegio diseñadas por la ciudad letrada. Las líneas de trabajo, con las lenguas del mapudungún y con el español de Chile, que ha abierto la poesía mapuche nos ha cen, a comienzos del siglo XXI, descubrir nuevas palabras, ampliar el horizonte, hallar el nuevo mundo.

\section{Obras citadas}

Aniñir, David. Mapurbe: Venganza de raíz. Santiago: Odiocracia autoediciones, 2005.

Berman, Marshall. Todo lo sólido se desvanece en el aire. México: Siglo XXI, 2006.

Bhabha, Homi. El lugar de la cultura. 1994. Buenos Aires: Manantial, 2002.

Barros, María José. "La(s) identidad(es) mapuche(s) desde la ciudad global en Mapurbe: Venganza de raíz de David Aniñir". Revista Chilena de Literatura 75. Noviembre, 2009: 29-46.

Cárcamo Huechante, Luis. "Tain pu a mulzugue egv: so nidos y voces del Wajmapu en el aire". Historia, colonialismo y resistencia desde el país mapuche. Ta Iñ Fijke Xipa Rakizuameluwün. Santiago: Ediciones Comunidad de Historia Mapuche, 2012: 341-358.

Carrasco, Iván. "Poesía mapuche etnocultural". Anales de Literatura Chilena 1. 2000: 195-214.

Colipán, Bernardo. Arco de interrogaciones. Santiago: LOM, 2005.

Chihuailaf, Elicura. El invierno, su imagen y otros poemas azules. Santiago: Ediciones literatura alternativa, 1991.

Consejo de todas las tierras. El pueblo mapuche y sus derechos fundamentales. Temuco: Consejo de todas las tierras, 1997.

Encina, Antonio. Historia de Chile. Tomo I. Santiago: Nascimento, 1952.

García Canclini, Néstor. Culturas híbridas. Buenos Aires: Paidós, 2005.

Hebdige, Dick. Subcultura. Barcelona: Paidós, 2004.

Hernández, Elvira. Santiago waria. Santiago: Cuarto Propio, 1996.

Huenún, Jaime. Ceremonias. Santiago: Editorial Universidad de Santiago, 1999. 20 poetas mapuches contemporáneos. Edición bilingüe. Santiago: LOM, 2003.

Huirimilla, Juan Pablo. Palimpesto. Santiago: LOM, 2005. 
Kotkin, Joel. La ciudad. Una historia global. Trad. Francisco Ramos. España: Debate, 2006.

Lienlaf, Leonel. Se ha despertado el ave de mi corazón. 1999. Santiago: Universitaria, 2008.

Monsiváis, Carlos. Amor perdido. México DF: Era, 2007.

Mora, Maribel y Fernanada Moraga. Antología poética de mujeres mapuche (siglos XX-XXI). Santiago: LOM, 2010.

Mora Curria, Maribel. "Poesía Mapuche del siglo XX: Escribir desde los márgenes del campo literario". Historia, colonialismo y resistencia desde el país mapuche. Ta Iñ Fijke Xipa Rakizuameluwün. Santiago: Ediciones comunidad de historia mapuche, 2012: 305-339.

Moraga, Fernanda. "A propósito de la diferencia. Poesía de mujeres mapuche". Revista Chilena de Literatura 74. 2009: 225-239.

Neruda, Pablo. "La lámpara en la tierra". Canto general. 1950. Bogotá: Oveja Negra, 1985: 4-7.

Rama, Ángel. "La ciudad letrada". Cultura urbana latinoamericana. Comp. Jorge Hardoy, Richard Morse et al. Buenos Aires: Clacso, 1985: 11-37.

Vicuña, Cecilia. ÜL: Four Mapuche Poets. Elicura Chihuailaf, Leonel Lienlaf, Jaime Huenún, Graciela Huinao. Pittsburgh: Latin American Literary Review, 1998.

Spivak, Gayatri. "Puede hablar el sujeto subalterno?". Trad. José Amícola. Revista Orbis Tertius 6, 1999: 175-235. 